\title{
Hubungan Lama Menderita Diabetes Melitus Dengan Nilai Ankle Brachial Index
}

\author{
Taufik Dwi Cahyono ${ }^{1}$, Okti Sri Purwanti ${ }^{2 *}$
}

1Universitas Muhammadiyah Surakarta, Surakarta 57162, Jawa Tengah, Indonesia

${ }^{2}$ Departemen Keperawatan Medikal Bedah, Universitas Muhammadiyah Surakarta, Surakarta 57162, Jawa

Tengah, Indonesia.

Korespodensi: Okti.Purwanti@ums.ac.id

\begin{abstract}
Abstrak: Lama menderita diabetes melitus tipe 2 menyebabakan penumpukan glukosa dalam darah yang mengakibatkan kerusakan pada pembuluh darah, sehingga menimbulkan risiko terjadinya komlikasi yang biasanya akan muncul pada 5-10 tahun. Pemeriksaan lanjutan yang diperlukan adalah dengan pengukuran Ankle brachial index (ABI) yang merupakan rasio tekanan darah pada ankle dan lengan. Tujuan penelitian ini adalah untuk mengetahui adanya hubungan antara lama menderita diabetes melitus dengan nilai ankle brachial index pada penderita diabetes melitus tipe2 di RSUD Dr. Moewardi Surakarta. Jenis penelitian ini adalah deskriptif korelatif dengan menggunakan pendekatan cross sectional. Sampel yang digunakan pada penelitian ini yaitu 30 pasien DM tipe 2 yang rawat inap di RSUD Dr. Moewardi Surakarta. Tehnik pengambilan sampel yang digunakan adalah consecutive sampling. Instrumen yang digunakan untuk mencatat data karakteristik menggunakan checklist, sphygmomanometer dan stetoskop. Hasil bivariat didapatkan bahwa responden yang memiliki nilai ABI normal dengan lama menderita DM 0,05) yang diartikan bahwa Ho diterima. Simpulan dari penelitian ini menunjukkan bahwa tidak terdapat hubungan antara lama menderita diabetes melitus dengan nilai ABI pada penderita diabetes melitus tipe 2 yang berarti bahwa lamanya menderita diabetes melitus tidak mempengaruhi keabnormalan nilai ABI.
\end{abstract}

Kata Kunci: Ankle Brachial Index, Diabetes Melitus, Lama menderita DM, Lama sakit, Gula darah.

\begin{abstract}
Duration of suffering diabetes melitus type 2 causes glucose increase in blood results in blood vessels damage, creates a risk of complications which will usually appear in 5-10 years. Further examination is needed is to measure Ankle brachial index (ABI), which is the ratio of blood pressure in the ankle and arm. The purpose of this research was to investigate the relationship between duration of diabetes melitus and an ankle brachial index in patients with type 2 diabetes melitus in Hospital Dr. Moewardi Surakarta. This research is a descriptive correlative with cross sectional approach. The sample used in this study 30 patients with type 2 diabetes melitus who were hospitalized in Dr. Moewardi Surakarta Hospital. Sampling technique used is consecutive sampling. The instrument used to record data are questionnaires, sphygmomanometer and stethoscope. Analysis of the data used is the chi square test. Bivariat results found that respondents who had normal ABI values with the duration of diabetes 0.05), which means that Ho is accepted. The conclusions of this study indicate that there is no relationship between duration of diabetes melitus with an ankle brachial index in patients with diabetes melitus type 2 whichmeans that the duration of diabetes melitus does noteffect the value abnormality ABI.
\end{abstract}

Keywords: Ankle Brachial Index, Diabeteic Mellitus, Duration of Diabetic Mellitus, Duration of Illness, Blood glucose. 


\section{PENDAHULUAN}

Diabetes Melitus (DM) adalah kelompok penyakit metabolic yang ditandai dengan tingginya kadar glukosa di dalam darah (hiperglikemi) yang terjadi akibat gangguan sekresi insulin, penurunan kerja insulin, atau akibat dari keduanya (American Diabetes Association (ADA), 2011). Prevelensi Diabetes Diabetes Melitus (DM) adalah kelompok penyakit metabolic yang ditandai dengan tingginya kadar glukosa di dalam darah (hiperglikemi) yang terjadi akibat gangguan sekresi insulin, penurunan kerja insulin, atau akibat dari keduanya (American Diabetes Association (ADA), 2011). Prevelensi Diabetes Melitus setiap tahunnya semakin meningkat, berdasarkan data dari WHO penderita DM dunia di tahun 2000 berjumlah 171 juta dan diperkirakan meningkat menjadi tiga kali lipatnya, yaitu sekitar 366 juta penderita di tahun 2030 (WHO, 2012).

Jumlah penderita diabetes melitus di Indonesia mencapai 8.4juta dan diperkirakan akan meningkat menjadi 21.2juta pada tahun 2030 (WHO, 2012). Di Jawa Tengah angka penderitayang terkena diabetes mencapai 125ribu (Profil Kes Jawa Tengah, 2011). Angka kejadian diabetes melitus pada tahun 2014 di Rumah Sakit Dr. Moewardi Surakarta mencapai jumlah 251.584 pasien rawat jalan dan 45.074 pasien rawat inap (Rekam Medik RSUD Dr. Moewardi Surakarta, 2015).

Penderita DM tipe 2 memiliki resiko komplikasi yang tidakjauhberbedadengan DM tipe 1 komplikasi yang mungkin terjadi pada penderita DM sangat komplek karena dapat menyerang organorgan vital tubuh. Komplikasi DM secaraumum di bagimenjadi 2 (dua), yaitu komplikasi akut (hipoglikemi, hiperglikemia ketoasidosis dan hiperglikemia hyperosmolar nonketotik) serta komplikasi kronis (PJK, penyakit serebrovaskular, hipertensi, infeksi, penyakit vascular parifer, penyakitarteriparifer, neuropati, retinopati, danulkus kaki diabetik) (Black \& Hawks, 2009). Komplikasi terjadi dalam kurun waktu 5-10 tahun setelah diagnosis di tegakkan (Smaltzer dan Bare, 2010).

Melitus setiap tahunnya semakin meningkat, berdasarkan data dari WHO penderita DM dunia di tahun 2000 berjumlah 171 juta dan diperkirakan meningkat menjadi tiga kali lipatnya, yaitu sekitar 366 juta penderita di tahun 2030 (WHO, 2012).

Jumlah penderita diabetes melitus di Indonesia mencapai 8.4juta dan diperkirakan akan meningkat menjadi 21.2 juta pada tahun 2030 (WHO, 2012). Di Jawa Tengah angka penderita yang terkena diabetes mencapai 125ribu (Profil Kes Jawa Tengah, 2011). Angka kejadian diabetes melitus pada tahun 2014 di Rumah Sakit Dr. Moewardi Surakarta mencapai jumlah 251.584 pasien rawat jalan dan 45.074 pasien rawat inap (Rekam Medik RSUD Dr. Moewardi Surakarta, 2015).

Penderita DM tipe 2 memiliki resiko komplikasi yang tidakjauhberbedadengan DM tipe 1 komplikasi yang mungkin terjadi pada penderita DM sangat komplek karena dapat menyerang organorgan vital tubuh. Komplikasi DM secaraumum di bagimenjadi 2 (dua), yaitu komplikasi akut (hipoglikemi, hiperglikemia ketoasidosis dan hiperglikemia hyperosmolar nonketotik) serta komplikasi kronis (PJK, penyakit serebrovaskular, hipertensi, infeksi, penyakit vascular parifer, penyakitarteriparifer, neuropati, retinopati, danulkus kaki diabetik) (Black \& Hawks, 2009). Komplikasi terjadi dalam kurun waktu 5-10 tahun setelah diagnosis di tegakkan (Smaltzer \& Bare, 2010).

Salah satu komplikasi dari diabetes melitus tipe 2 yang mempengaruhi sistem saraf parifer yaitu Paripheral Arthery Disease (PAD) merupakan suatu kondisi dimana terdapat lesi di pembuluh darah sehingga menyebabkan aliran darah dalam arteri yang mensuplaidarah ke ekstremitas menjadi terbatas dan penyakit ini juga sangat ditakuti karena mempengaruhi kualitas hidup dan fungsi sosial penderitanya (Williams \& Wilkins, 2011).

Terdapat hubungan yang kuat antara lama menderita DM dan gangguan sirkulasi perifer,kadar gula di dalam darah yang tinggi secara terus menerus dapat merubah dan merusak jaringan pembuluh darah. Pemeriksaan lanjutan yang diperlukan pada kecurigaan adanya PAD adalah pengukuran Ankle brachial index(ABI) yang merupakan rasio tekanan darah pada ankle dan brachial. Nilai ABI dianggap normal apabila $\geq 1.0$ sedangkan nilai $\mathrm{ABI} \leq 0.9$ dapat membantu menegakkan diagnosis PAD (Williams \& Wilkins, 2011). 
Lama seseorang yang menderita diabetes melitus lebih dari 20 tahun dapat mempengaruhi nilai ABI yaitu dilakukan oleh Azwaldi (2012) yang menyatakan bahwa tidak ada hubungan antara lama responden menderita diabetes melitus dengan nilai ABI responden, dengan nilap $p$ value $=0,366$.

Adanyaperbedaandurasipadap enderita diabetes mellitus mengakibatkan nilai ABI pada setiap penderita diabetes melitus berbeda-beda Meskipun lama seseorang menderita diabetes mellitus dapat mempengaruhi nilai $\mathrm{ABI}$, namun pada kenyataannya beberapa penelitian menunjukkan hasil yang berbeda-beda. Hal ini dikarenakan masih jarangnya penelitian yang mencoba menghubungkan antara lama menderita diabetes mellitus dengan nilai ABI. Berdasarkan uraian diatas peneliti tertarik untuk melakukan penelitian yang berjudul "Hubungan Antara Lama Menderita Diabetes Melitus dengan Nilai Ankle Brachial Index Pada Penderita Diabetes Melitus Tipe2 Di RSUD Dr. Moewardi Surakarta?"

\section{METODE}

Jenis penelitian ini adalah kuantitatif, dengan rancangan jenis penelitian deskripsi korelatif atau penelitian yang menjelaskan ada tidaknya hubungan antara variabel bebas dan variabel terikat melalui pengujian hipotesis. Sedangkan pengambilan data menggunakan pendekatan cross sectional atau potong lintang yaitu suatu metode penelitian yang dilakukan di mana variabel tergantung (efek) diobservasi sekaligus pada waktu yang sama, penelitian ini dilakukan untuk melihat hubungan antara variabel satu dengan yang lainnya dan dikumpulkan secara simultan atau pada suatu waktu (point time approach) (Natoadmodjo, 2010).

Populasi dalam penelitian ini adalah pasien DM tipe 2 yang rawat inap di Bangsal Melati 1 dan Melati 3 RSUD Dr. Moewardi Surakarta. Teknik sampling yang digunakan untuk pengambilan sampel dalam penelitian ini adalah consecutivesampling, dengan jumlah sampel 30 responden.

Penelitian ini menggunakan lembar checklistyang digunakan untuk mencatat karakteristik responden berisi inisial, usia, riwayatmerokok, riwayat mengkonsumsi alkohol dan riwayat olahraga. Sedangkan instrumen untuk mengetahui nilai ABI menggunakan Sphygmomanometer dan Stetoskope.

Analisis dilakukan untuk mencari hubungan antara lama menderita DM dengan nilai ABI pada penderita DM. Uji yang digunakan adalah uji Chi Square.

\section{HASIL PENELITIAN}

Penelitian ini dilakukan di Rumah Sakit Umum Daerah Dr. MoewardiSurakarta. Responden dalam penelitian ini adalah penderita diabetes melitus tipe 2 yang berada di ruang Melati 1 dan Melati 3. Jumlah sampel dalam penelitian ini adalah 30 responden. Data karakteristik responden dalam penelitian ini adalah:

Tabel 1 Karakteristik Responden

\begin{tabular}{lcc}
\hline \multicolumn{1}{c}{ Karakteristik } & Frekuensi & Presentase (\%) \\
\hline Riwayat Merokok & & \\
$\quad$ Merokok & 14 & 46,7 \\
$\quad$ Tidak Merokok & 16 & 53,3 \\
Riwayat Olahraga & & \\
$\quad$ Olahraga & 17 & 56,7 \\
$\quad$ Tidak Olahraga & 13 & 43,3 \\
Konsumsi Alkohol & 0 & 0 \\
$\quad$ Mengkonsumsi Alkohol & 30 & 100 \\
$\quad$ Tidak mengkonsumsi Alkohol & & 0 \\
Usia & 0 & 66,7 \\
$\quad$ Dewasa awal (21-44 tahun) & 20 & 33,3 \\
$\quad$ Dewasa menengah (45-60 tahun) & 10 & $\mathbf{1 0 0}$ \\
$\quad$ Lansia (>60 tahun) & $\mathbf{3 0}$ & \\
\hline Total & & \\
\hline
\end{tabular}


Tabel 2 Karakteristik lama menderita diabetes melitus tipe 2

\begin{tabular}{cccccc}
\hline Karakteristik & Mean & Median & Mode & Min. & Max \\
\hline Lama menderita DM & 6,37 & 5,50 & 4 & 1 & 13 \\
\hline
\end{tabular}

Tabel 2 diketahui rerata lama menderita diabetes mellitus tipe 2 pada responden adalah 5,50 tahun, minimum 1 tahun dan maksimum 13 tahun.

Tabel 3 Distribusi lama menderita diabetes mellitus tipe 2

\begin{tabular}{ccc}
\hline Lama menderita Diabetes Melitus & Frekuensi & Presentase \\
\hline$<5$ tahun & 13 & 43,3 \\
$\geq 5$ tahun & 17 & 56,7 \\
\hline Jumlah & $\mathbf{3 0}$ & $\mathbf{1 0 0}$ \\
\hline
\end{tabular}

Tabel 4 Karakteristik nilai ABI

\begin{tabular}{cccccc}
\hline Karakteristik & Mean & Median & Mode & Min. & Max \\
\hline Nilai ABI & 0,95 & 0,94 & 0,84 & 0,76 & 1,20 \\
\hline
\end{tabular}

Tabel 5 Distribusi nilai ankle brachial index

\begin{tabular}{ccc}
\hline Nilai ABI & Frekuensi & Persentase (\%) \\
\hline Normal & 16 & 60 \\
Abnormal & 14 & 40 \\
\hline Jumlah & $\mathbf{3 0}$ & $\mathbf{1 0 0}$ \\
\hline
\end{tabular}

Tabel 6 Crosstabulasi antara lama menderita diabetes melitus dengan nilai Ankle Brachial Index

\begin{tabular}{|c|c|c|c|c|c|c|}
\hline \multirow{3}{*}{ Lama menderita diabetes } & \multicolumn{4}{|c|}{ Nilai ABI } & \multirow{3}{*}{$\begin{array}{c}\text { Total } \\
\mathbf{N}\end{array}$} & \multirow{3}{*}{$\begin{array}{c}\text { Total } \\
\% \\
\end{array}$} \\
\hline & \multicolumn{2}{|c|}{ Normal } & \multicolumn{2}{|c|}{ Abnormal } & & \\
\hline & $\mathbf{N}$ & $\%$ & $\mathbf{N}$ & $\%$ & & \\
\hline$<5$ tahun & 9 & 69 & 4 & 30 & 13 & 100 \\
\hline$\geq 5$ tahun & 9 & 52, & 8 & 47 & 17 & 100 \\
\hline Total & 18 & $6 C$ & 12 & 46 & 30 & 100 \\
\hline
\end{tabular}

$p=0,814 \quad \mathrm{Ho}=$ diterima

Hasil yang didapatkan dari uji chi square adalah nilai $p$-value $=0,814$ yang berarti nilai $p$-value $>0,05$ yang dapat diartikan bahwa Ho diterima dan Ha ditolak. Sehingga dapat disimpulkan bahwa tidak terdapat hubungan antara lama menderita diabetes melitus dengan ankle brachial index pada penderita diabetes melitus tipe dua di Rumah Sakit Umum Daerah dr.Moewardi Surakarta

\section{PEMBAHASAN}

\section{Karakteristik Responden Hasil}

Hasil dari penelitian ini menunjukkan bahwa responden yang tidak merokok sebanyak 53,3\% responden, sedangkan yang merokok yaitu sebanyak 46,7\% responden. Kebiasaan merokok dapat berpengaruh terhadap munculnya komplikasi-komplikasi pada penderita diabetes melitus contohnya, CVD (Cardivascular Disease) dan PAD, (America Diabetic Association (ADA), 2015). Hal ini sejalan dengan penelitan yang dilakukan oleh Turns (2011) yang menyebutkan bahwa merokok dapat meningkatkan risiko PAD sebesar 2,11 kali dibandingkan dengan yang tidak merokok. 
Selain riwayat merokok, olahraga juga dapat mempengaruhi diabetes melitus tipe 2 pada individu yang berisiko tinggi (America Diabetic Association (ADA), 2015). Dengan berolahraga glukosa dalam darah dibakar menjadi energi sehingga sel-sel energi menjadi sensitive terhadap insulin, peredaran darah menjadi lebih baik dan resiko terjadinya diabetes melitus tipe 2 berkurang hingga 50\% (Turns, 2011). Dalam penelitian ini didapatkan hasil responden yang melakukan olahraga sebesar $56.7 \%$ dan yang tidak melakukan olahraga sebesar $43,3 \%$. Hal tersebut didukung oleh penelitian yang dilakukan oleh Chen (2015) yang menyatakan bahwa terdapat hubungan yang signifikan antara olahraga dengan kejadian DM tipe 2 dan memberikan risiko kejadian DM tipe 2 sebesar 0,89 kali.

Konsumsi alkohol dapat mempengaruhi kelenjar endokrin, dengan melepaskan epinefrin yang mengarah kepada hiperglikemi transient dan hyperlipidemia sehingga konsumsi alkohol kontraindikasi dengan diabetes melitus (Irawan, 2010). Penelitian yang dilakukan Wahyuni (2010) yang mengatakan bahwa seseorang yang mengkonsumsi alkohol dapat berisiko 0,40 kali untuk mengalami penyakit diabetes melitus, kemudian berdasarkan analisis uji multivariate didapatkan bahwa konsumsi alkohol mempengaruhi kejadian diabetes melitus setelah dikontrol oleh variable umur, pekerjaan, obesitas, dan konsumsi kafein dengan OR terendah dari variable lainnya. Hal tersebut berarti konsumsi alkohol adalah variable yang paling rendah mempengaruhi kejadian diabetes melitus.

Meningkatnya kadar glukosa darah erat kaitannya dengan pertambahan usia, sehingga semakin meningkat usia maka prevalensi diabetes dan gangguan toleransi glukosa semakin tinggi. Hasil dari penelitian ini menunjukkan bahwa sebagian besar responden berada pada usia dewasa menengah(45-60 tahun) yaitu $66,7 \%$ responden. Hasil yang sama juga diperoleh pada penelitian yang dilakukan oleh Yuhelma (2014) yang menyatakan bahwa responden yang menderita diabetes melitus tipe 2 mayoritas berada pada usia 45-60 tahun yaitu sebesar 65,3\%.

\section{Lama menderita diabetes melitus}

Berdasarkan hasil penelitian yang telah dilakukan didapatkan hasil bahwa 56,7\% responden mempunyai riwayat diabetes melitus $\geq 5$ tahun sedangkan $43,3 \%$ responden mempunyai riwayat siabetes melitus $<5$ tahun. Semakin lama seseorang mengalami diabetes melitus maka semakin besar risiko terjadinya komplikasi-komplikasi yang akan muncul, seperti ulkus diabetes, retinopati, nefropati, neuropati, CAD, dan PAD (LeMone, Burke, and Bauldoff, 2011).

Hal ini sejalan dengan penelitian yang dilakukan oleh Dodie (2013) yang menyatakan bahwa terdapat hubungan antara lama menderita diabetes melitus terhadap terjadinya disfungsi ereksi dengan $p=$ 0,025 dengan signifikansi 0,05. Sehingga semakin lama menderita diabetes melitus akan mengakibatkan terjadinya disfungsi ereksi.

\section{Nilai Ankle Brachial Index}

Hasil penelitian yang telah dilakukan didapatkan hasil bahwa $60 \%$ memiliki nilai ABI normal dan $40 \%$ memiliki nilai ABI abnormal. Hal ini dapat disebabkan karena sebagian besar responden tidak memiliki riwayat merokok dan tidak mengkonsumsi alkohol. Konsumsi alkohol dapat berisiko memperparah kondisi sirkulasi perifer dan aliran darah pasien diabetes melitus, sedangkan kebiasaan merokok dapat mempengaruhi terjadinya gangguan peredaran darah pada kaki, sehingga dapat berpengaruh terhadap nilai ankle brachial index. Merokok dapat mempengaruhi nilai ABI, saat seseorang merokok 10 menit sebelum dilakukan pemeriksaan ABI, dapat menurunkan nilai ABI sebesar 0,09 unit (Marius, Luminita, Maria, \&Crina, 2014).

\section{Hubungan antara lama menderita diabetes melitus tipe 2 dengan nilai ankle brachial index}

Penelitian ini menunjukkan bahwa tidak terdapat hubungan antara lama menderita diabetes melitus dengan nilai ankle brachial index. Hasil tersebut sejalan dengan penelitian yang dilakukan oleh Azwaldi (2012) yang menunjukkan bahwa tidak terdapat hubungan antara lama menderita DM yang dialami responden dengan nilai ankle brachial index pada pasien Diabetes Melitus di Poliklinik Penyakit Dalam RSUP Dr. M. Hoesin Palembang dengan nilai $p$ 0,366. Tapiheru (2008) juga menyatakan bahwa tidak 
dijumpai perbedaan yang signifikan antara lamanya menderita diabetes melitus dengan nilai ABI pada penderita diabetes melitus di RSUP. H. Adam Malik Medan dengan $\mathrm{p}=0,766$. Hasil penelitian ini tidak sejalan dengan penelitian Chen, Wang \& Zhao (2015) yang menyatakan bahwa terdapat hubungan antara lama menderita dibeetes melitus dengan nilai ABI pada penderita diabetes melitus tipe 2 di Department of Endocrinology, Beijing Tongren Hospital, Capital Medical University dengan $p=0,014$.

Lama menderita diabetes melitus tidak berdiri sendiri sebagai faktor memburuknya nilai ABI. Lama menderita diabetes melitus, riwayat merokok, riwayat alkohol, latihan fisik (olahraga) dan usia akan mempengaruhi nilai ABI yang menyebabkan risiko terjadinya PAD (Kirsner, 2010). Hasil penelitian ini tidak berhubungan kemungkinan disebabkan karena lama responden menderita dibetes melitus rata-rata 5,50 tahun, kurun waktu ini belum cukup lama untuk mencetuskan adanya kerusakan pembuluh darah arteri perifer, seperti yang dijelaskan oleh Escobedo, Rana, Lombardero, et al (2010) bahwa PAD dan kerusakan fungsi miokard akan terlihat pada penderita diabetes melitus yang menderita diatas 20 tahun.

Faktor lain yang dapat mempengaruhi nilai ABI adalah usia, riwayat merokok, olahraga dan alkohol. Berdasarkan data penelitian, dari 12 responden yang memiliki nilai ABI abnormal, 10 diantaranya berada pada usia lansia ( $>60$ tahun ). Responden yang memiliki riwayat merokok sebanyak 6 responden dan 6 responden lain memiliki riwayat tidak pernah berolahraga. Mayoritas responden tersebut menderita diabetes melitus $\geq 5$ tahun, yaitu sebanyak 8 respondendan keseluruhan responden tidak ada yang memiliki riwayat mengkonsumsi alkohol. Instrumen dalam penelitian ini tidak menggunakan Doppler melainkan diganti dengan stetoscope dimana frekuensi suara yang dikeluarkan saat mendengarkan denyut nadi tidak sebesar kalau menggunakan Doppler, sehingga masih ada kemungkinan terjadi kesalahan saat melakukan pemeriksaan ABI.Artinya tidak hanya lama menderita diabetes melitus yang mempengaruhi nilai ABI, tetapi juga masih ada faktor lainnya yang dapat mempengaruhi nilai ABI.

\section{KESIMPULAN}

Berdasarkan penelitian yang telah dilakukan, dapat disimpulkan bahwa lama responden menderita diabetes melitus dalam penelitian ini sebagian besar adalah $\geq 5$ tahun. Hasil pemeriksaan ankle brachial indek pada responden menunjukkan bahwa mayoritas responden memiliki nilai ABI normal.Sehingga dapat disimpulkan bahwa tidak terdapat hubungan antara lama menderita diabetes melitus dengan nilai ankle brachial index pada penderita diabetes melitus tipe dua.

Berdasarkan penelitian yang telah dilakukan, saran yang dapat diberikan oleh peneliti antara lain: (1) Bagi penderita diabetes mellitus diharapkan penderita dapat memeriksakan diri ke pelayanan kesehatan, sehingga dapat mendeteksi lebih awal keruskan pada pembuluh darah seperti PAD, CAD, ulkus, dan penyakit kardiovaskular lainnya, salah satunya dengan melakukan pemeriksaan ankle brachial index. (2) Bagi institusi pelayanan kesehatan diharapkan dengan adanya penelitian ini, institusi pelayanan kesehatan bias memfasilitasi penderita untuk pemeriksaan ankle brachial index rutin untuk mendeteksi sedini mugkin keruskan pada pembuluh darah seperti PAD, CAD, ulkus, dan penyakit kardiovaskular lainnya., dan mampu mensosialisasikan bahwa pemeriksaan ABI penting. (4) Bagi Institusi Pendidikan bagi institusi pendidikan hendakyna mampu untuk mengaplikasikan pemeriksaan ankle bracia index dalam metode belajar mengajar dan dapat dijadikan publikasi ilmiah. (5) Bagi peneliti lain perlu penelitian lebih lanjut dengan metode yang sama ataupun yang berbeda dan meneliti faktor risiko lain yang dapat mempengaruhi nilai ABI. Untuk peneliti selanjutnya diharapkan dalam melakukan pemeriksaan nilai ABI menggunakan Doppler untuk mengurangi terjadinya kesalahan dalam pengukuran,mengingat penelitian ini menggunakan stetoscope yang frekuensi suaranya tidak sebesar Doppler.Apabila penelitian selanjutnya tetap menggunakan stetoscope, akan lebih baiknya jika menggunakan stetoscope yang bercabang 2 dengan bantuan asisten, sehingga dapat membandingkan antara suara denyut nadi yang didengar peneliti dengan suara nadi yang didengar asisten dan dapat meminimalisir terjadinya kesalahan, karena jika menggunakan stetoscope dengan cabang 1 hasil yang didapat hanya tergantung pada pendengaran peneliti seorang, yang menyebabkan kemungkinan terjadinya kesalahan dalam menentukan hasil dari pemeriksaan nilai ABI. Peneliti selanjutnya dapat menambahkan jumlah responden yang lebih banyak dengan kriteria inklusi dan eksklusi yang lebih ketat sehingga akan diperoleh hasil yang lebih representatif.Semoga penelitian ini dapat menjadi data dasar dalam penelitian yang lebih luas mengenai ankle bracal index. 


\section{DAFTAR PUSTAKA}

American Diabetes Association/ADA. (2011). Standart of Medical Care in Diabetes-2011. Journal Diabetes Care, 34: 511-561.

American Diabetes Association. (2015). Standards of Medical Care in Diabetic. Vol 38, S20-S30.

Azwaldi, S. W. (2012). Faktor-Faktor Yang Berhubungan Ankle Brachial Pressure Index Di Poli Penyakit. Skripsi.

Black J.M., \& Hawks J.H. (2009). Medical-Surgical Nursing: Clinical Management for Positive Outcomes. 8Th Edition Singapore: Elseveir Saunders.

Chen, Y.W., Wang, Y.Y., Zhao., D. (2015). High Prevalence of Lower Extremity Peripheral Artery Disease in Type 2 Diabetes Patients with Proliferative DiabeticRetinopathy. University of Leipzig. Germany

Dinas Kesehatan Provinsi Jawa Tengah. (2011). Profil Kesehatan Provinsi Jawa Tengah tahun 2011. Dinas Kesehatan Provinsi Jawa Tengah. Surakarta

Dodie, N.J. (2013). Pengaruh Lamanya Diabetes Melitus Terhadap Terjadinya Disfungsi Ereksi. Skripsi Ilmiah. Fakultas Kedokteran Universitas Sam Ratulangi. Manado

Irawan D. (2010). Prevalensi dan Faktor Risiko Kejadian Diabetes Melitus Tipe 2 di Daerah Urban di Indonesia. Tesis. Jakarta : FKMUI

Kirsner, R.S. (2010). The Standart of Care for Evaluation and Treatment of Diabetic Foot Ulcers.

LeMone, P., Burke, K., \& Bauldoff, G. (2011). Medical Surgical Nursing Critical Thinking in Client Care, vol 1. (4thed), Pearson Education. Canada

Marius, R.A, Maria, G., \& Crina, S. (2014). The Role of Ankle-Brachial Index for Predicting Peripheral Artery Disease. Univercity of Medicine and Pharmacy. Bucharest: Romania.

Notoatmodjo, S. (2010). Metode Penelitian Kesehatan. Jakarta : Rineka Cipta.

Rekam Medik, RSUD Dr. Moewardi Surakarta. (2015). Data Angka Kejadian Diabetes Melitus tahun 2014. Surakarta: RSUD Dr. Moewardi Surakarta

Smeltzer \& Bare. (2010). Textbook of Medical Surgical Nursing Vol 2. Philadhelphia: Linppincott

Tapiheru, L.A. (2008). Hubungan nilai ABI dengan Skor MMSE dan CDT pada Penderita PAD. Karya Ilmiah. Medan : Fakultas Kedokteran Universitas Sumatera Utara Medan.

Turns, M. (2011). The Diabetic Foot: An Overview of Assesment and Complication. British Journal of Nursing, 20 (15), S 19-25

Wahyuni, S. (2010). Faktor-Faktor yang Berhubungan dengan Penyakit Diabetes Melitus (DM) Daerah Perkotaan Indonesia tahun 2007. Skripsi Ilmiah. Jakarta: Fakultas Kedokteran dan Ilmu Kesehatan Universitas Islam Negeri Syarif Hidayatullah Jakarta.

Williams, L., \& Wilkins. (2011). Nursing: Memahami Berbagai Macam Penyakit. Alih Bahasa Paramita. Jakarta: PT. Indeks

World Health Organisation. (2012). Prevalence of diabetes worldwide: Country and Regional data on diabetes. http://www.who.int

Yuhelma, dkk. (2014). Identifikasi dan Analisis Komplikasi Makrovaskular dan Mikrovaskular pada Pasien Diabetes Melitus. Skripsi Ilmiah. Riau: Program Study Ilmu Keperawatan Universitas Riau. 